\title{
Investigation of Nanoporous Platinum Thin Films Fabricated by Reactive Sputtering: Application as Micro-SOFC Electrode
}

\author{
WooChul Jung ${ }^{\S, a, b}$, Jae Jin Kim ${ }^{\S, a}$, Harry L. Tuller $*^{a}$
}

${ }^{\S}$ Both authors contributed equally to this work.

${ }^{\mathrm{a}}$ Department of Materials Science and Engineering, Massachusetts Institute of Technology, Cambridge, Massachusetts, 02139, USA

${ }^{\mathrm{b}}$ Department of Materials Science and Engineering, Korea Advanced Institute of Technology, Daejeon, 305701, South Korea

*E-mail: tuller@mit.edu, phone: 1-617-253-6890, fax: 1-617-258-5749

Keywords: Micro Solid Oxide Fuel Cell; Oxygen Reduction Reaction; Porous Platinum; Reactive Sputtering; Thin Film

\begin{abstract}
Highly porous Pt thin films, with nano-scale porosity, were fabricated by reactive sputtering. The strategy involved deposition of thin film $\mathrm{PtO}_{\mathrm{x}}$ at room temperature, followed by the subsequent decomposition of the oxide by rapid heat treatment. The resulting films exhibited percolating Pt networks infiltrated with interconnected nanosized pores, critical for superior solid oxide fuel cell cathode performance. This approach is particularly attractive for microfabricated solid oxide fuel cells, since it enables fabrication of the entire cell stack (anode/electrolyte/cathode) within the sputtering chamber, without breaking vacuum. In this work, the morphological, crystallographic and chemical properties of the porous electrode were systematically varied by control of deposition conditions. Oxygen reduction reaction kinetics were investigated by means of electrochemical impedance spectroscopy, demonstrating the critical role of nano-pores in achieving satisfactory micro-SOFC cathode performance.
\end{abstract}




\section{Introduction}

Micro solid oxide fuel cells ( $\mu$-SOFC) promise considerably higher energy densities than lithium batteries for portable power generation in devices such as laptop computers and mobile telephones and therefore have attracted recent interest.[1-4] These $\mu$-SOFCs rely on self-supporting, multilayer stacks, including a thin film solid electrolyte (e.g. yttria stabilized $\mathrm{ZrO}_{2}$ or acceptor doped $\mathrm{CeO}_{2}$ ) sandwiched between thin film electrodes. This offers the possibility of embedding miniaturized SOFC structures, together with MEMS components, and other active electronics, within the same silicon wafer or other planar-like structures.[3,4] Thin film versus standard ceramic SOFC processing also promises significantly reduced processing and operating temperatures, leading to extended life and reduced cost.[2-6] Given considerably reduced operating temperatures, more catalytically active electrodes are necessary, and this work aims to develop strategies for enhancing the activity of SOFC electrodes, compatible with wafer scale process, at reduced temperatures.

Platinum $(\mathrm{Pt})$ is viewed as an attractive choice as an electrode in micro-electrochemical devices, due to its process compatibility with MEMS and microelectronic devices, excellent catalytic activity, and high electronic conductivity.[7] Considering that electrochemical reactions at both SOFC electrodes simultaneously involve gas, electronic and ionic species, a highly porous and continuously connected Pt structure with high triple phase boundary length, serving as a gas permeable and electronic conducting layer, as well as a electrocatalyst, is necessary.[8] The most common strategies for fabricating such porous Pt structures are based on replication or modification of sacrificial porous molds, either inorganic or polymeric.[911] These templating techniques have the advantage of precise control over the size and microstructure of the final porous metal structures, but are generally difficult and time consuming to implement. An alternative means for creating porous structures is by a selective dissolution method, known as dealloying.[12-16] It involves selective electrolytic dissolution of a less-noble element from a mixture of intermetallic compounds, leaving behind a 
nanoporous framework. However, it often suffers from contamination by incomplete removal of the less-noble element, which may result in degraded catalytic properties.[17,18] Furthermore, both of the above-mentioned methods typically utilize wet chemical methods, that are often incompatible with the clean and controlled vacuum environment required in the fabrication of micro devices. Lastly, porous structure can be prepared from pure metal thin films as a result of Ostwald ripening, without aid of sacrificial templates or elements, by postannealing dense films at high temperature[7,19,20] or by depositing at high pressure. $[4,5]$ However, reproducible porous structures are not easily obtained, given the inability to precisely control multiple critical variables including rate, temperature and pressure for deposition, annealing temperature and duration, and film thickness uniformity.[3,7]

In this work, we investigate an alternative approach based on the reactive sputtering of platinum in an oxygen containing atmosphere to deposit platinum oxide $\left(\mathrm{PtO}_{\mathrm{x}}\right)$ films that, upon subsequent high temperature anneal, are converted back to Pt with consequent formation of nanoporosity. While a similar approach was recently described by Cho et. al.,[21] a detailed analysis regarding the formation of $\mathrm{PtO}_{\mathrm{x}}$ and the role of the oxygen in creating porosity was not provided. Here, we examine this aspect in some detail. The morphological and chemical properties of the porous Pt thin films are systematically controlled by changing deposition atmosphere, and are investigated by means of SEM, XRD, and XPS. Furthermore, no attempt was made in the previous study to examine the electrochemical activity of the resultant structures as a function of porosity and film thickness. Here, the electrochemical performance of porous Pt thin films (as a potential SOFC cathode), deposited onto both sides of a single crystal yttria-stabilized zirconia electrolyte (YSZ) substrate, is thoroughly investigated with the aid of electrochemical impedance spectroscopy (EIS). The complex impedance data are analyzed and compared with previous results reported for various porous Pt electrodes on YSZ, demonstrating the critical role of nano-porosity in achieving satisfactory cathode performance. 


\section{Experimental}

\subsection{Nanoporous $P t$ thin film fabrication}

Porous Pt thin films were produced by reactive magnetron sputtering (Kurt J. Lesker, Clairton, PA), at a DC power of $50 \mathrm{~W}$, from a two-inch diameter metal target of $99.99 \%$ pure Pt (ACI Alloys), under controlled argon/oxygen atmosphere, with subsequent annealing in air at elevated temperature. The total chamber pressure was maintained at $10 \mathrm{mTorr}$ after pumping the background pressure down to less than $3 \times 10^{-6}$ Torr. Controlled concentrations of argon and oxygen were introduced into the sputtering chamber at argon to oxygen ratios between 9:1 and 3:7, in order to reactively sputter $\mathrm{PtO}_{\mathrm{x}}$ films. The substrate was unheated, but the substrate surface temperature increased to approximately $180{ }^{\circ} \mathrm{C}$ during deposition. Following deposition, the films were quickly heated to $600{ }^{\circ} \mathrm{C}$ in air for an hour to decompose the platinum oxides and subsequently quenched to room temperature (RT).

\subsection{Structural and chemical characterization}

The morphology of the resulting films was characterized by scanning electron microscopy (SEM, FEI/Philips XL30 FEG ESEM), showing highly porous films with nano-scale porosity. The thickness of as-deposited $\mathrm{PtO}_{\mathrm{x}}$ films was determined by surface profilometry (KLATencor Alpha-Step P-10). Chemical compositions and bonding states were investigated in a Kratos Analytical (Manchester, UK) model Axis Ultra X-ray photoelectron spectrometer (XPS). CasaXPS software was used for peak-fitting and chemical quantification. A monochromated aluminum x-ray source of $1486.6 \mathrm{eV}$ was used at a power of $150 \mathrm{~W}$. Pass energies of $160 \mathrm{eV}$ and $20 \mathrm{eV}$ were used for survey and high resolution scans, respectively. Binding energy values were calibrated by setting the peak energy of the 1s electron in carbon, found as a surface contaminant in open air, to $285.0 \mathrm{eV}$.

\subsection{Electrochemical performance}


A symmetric structure, with identically sized $(9 \mathrm{~mm}$ x $9 \mathrm{~mm}$ ) porous Pt electrodes on both sides of the YSZ electrolyte, was used for electrochemical impedance spectroscopy (EIS) measurements. Both a custom-designed enclosed probe station, manufactured by McAllister Technical Services (Coeur d'Alene, ID) and a tube furnace were used for the EIS measurements at temperatures between $315^{\circ} \mathrm{C}$ and $450{ }^{\circ} \mathrm{C}$ in air. EIS measurements, covering the frequency range from $16 \mathrm{mHz}$ to $1 \mathrm{MHz}$, with amplitude of $20 \mathrm{mV}$, were performed with a Solarton 1260 impedance analyzer.

\section{Results and Discussion}

\subsection{Morphological and chemical properties of the porous $\mathrm{Pt}$ thin films}

The strategy for the fabrication of porous Pt thin films involves the deposition of thin film $\mathrm{PtO}_{\mathrm{x}}$ at room temperature, followed by the subsequent decomposition of the oxide by heat treatment. Figure 1 shows SEM images of the resulting Pt films after thermal decomposition of the platinum oxides at $600{ }^{\circ} \mathrm{C}$ for one hour for sputtering atmospheres of $\mathrm{O}_{2} /\left(\mathrm{O}_{2}+\mathrm{Ar}\right)=10$, 20, 25, 30, 50 and 70, on a percentage basis, utilized during sputtering. (The as-deposited films have the same thickness, $\sim 200 \mathrm{~nm}$.) A highly porous microstructure with tens of nanometer sized pores was obtained only for $\mathrm{O}_{2} /\left(\mathrm{O}_{2}+\mathrm{Ar}\right)$ ratios higher than $30 \%$; while a dense film was obtained for $\mathrm{O}_{2} /\left(\mathrm{O}_{2}+\mathrm{Ar}\right)$ ratios of less than or equal to $20 \%$. The onset of pore formation just begins at an $\mathrm{O}_{2} /\left(\mathrm{O}_{2}+\mathrm{Ar}\right)$ ratio of $25 \%$. Temperatures higher than $600{ }^{\circ} \mathrm{C}$ were not used during subsequent annealing, given that the goal of this study was to find a process compatible with typical micro-fabrication schemes that operate under restricted thermal budgets.

The Pt/O binary system is highly immiscible with a limited oxygen solubility of only 19 ppm even at $1450{ }^{\circ} \mathrm{C}$ and 1 atm of oxygen.[22] However, $\mathrm{Pt}$ oxidic compounds $\left(\mathrm{PtO}_{\mathrm{x}}\right)$ can be formed under certain conditions, such as at relatively extreme conditions of pressure and temperature,[23] under highly anodic potentials in aqueous solution,[24] and under $\mathrm{Ar} / \mathrm{O}_{2}$ 
plasma conditions.[21,25-32] In addition, once formed, $\mathrm{PtO}_{\mathrm{x}}$ is unstable at intermediate temperatures, with none of the oxides (i.e. amorphous $\mathrm{PtO}_{\mathrm{x}}, \mathrm{PtO}$ and $\mathrm{PtO}_{2}$ ) known to be thermodynamically stable above $350{ }^{\circ} \mathrm{C} .[31-33]$ Sputtering allows oxygen to react with $\mathrm{Pt}$ metal and maintain a metastable Pt-O bond, provided the chamber is maintained at a relatively high oxygen partial pressure, when combined with a low deposition temperature. During subsequent heating, $\mathrm{PtO}_{\mathrm{x}}$ decomposes with accompanying loss of oxygen, resulting in highly porous Pt thin films with nano-scale porosity (see Figure 1). For Pt operating as electrodes in SOFCs, the electrochemical reactions are confined to the three-phase-boundary (tpb) where gas, electrolyte and electrode meet together.[8,34,35] Accordingly, a high tpb-length, coexisting with networks enabling simultaneous electronic and oxygen percolation pathways to access the tpb, are considered crucial for superior electrochemical performance of $\mathrm{Pt}$ electrodes deposited onto solid oxide electrolytes such as YSZ.

Previously, similar strategies for obtaining porous Pt films were attempted by reducing the sputtered $\mathrm{PtO}_{\mathrm{x}}$ layers with hydrogen gas or by electrochemical means at room temperature.[36,37] Despite the resulting high surface area of the Pt layer, these techniques do not create pores that completely penetrate through the Pt layer, resulting in limited accessibility of the oxygen gas molecules to the solid electrolyte surface. Furthermore, the room-temperature-reduced Pt structures are unlikely to remain thermally stable at the operating temperature of the micro-SOFC, e.g., $>350{ }^{\circ} \mathrm{C}$. The Pt thin films obtained in this work, in contrast, provide a percolating Pt network with continuous pathways for the oxygen gas via the interconnected pores. In addition to enhanced thermal stability characteristic of our films, our method is also more generally applicable to other materials systems, for example, nanoporous Au and Ni thin films (see Supporting Information Figure S1).

The deposition atmosphere was controlled by varying the argon to oxygen gas ratio, $\mathrm{O}_{2} /\left(\mathrm{O}_{2}+\mathrm{Ar}\right)$, from $10 \%$ to $70 \%$, while maintaining the same total pressure of 10 mTorr. The formation of the Pt oxide phases in as-deposited films was first confirmed by XPS analysis of 
the $\mathrm{Pt} 4 f$ electron, exhibiting three different bonding states (i.e., $\mathrm{Pt}, \mathrm{PtO}$ and $\mathrm{PtO}_{2}$ ) as shown in Figure 2a. While pure $\mathrm{Pt}$ is reported to show two energy states at $71.2 \sim 3 \mathrm{eV}$ and $74.6 \mathrm{eV}$ for $4 f_{7 / 2}$ and $4 f_{5 / 2}$, respectively, the corresponding energy states of $\mathrm{PtO}$ and $\mathrm{PtO}_{2}$ are shifted to higher energies i.e., 72.3 4 eV / 75.6 7 eV and 73.6 74.2 eV / 76.8 77.5 eV, respectively.[26,38] The atomic ratio between $\mathrm{O}$ and $\mathrm{Pt}$ in the as-deposited films is also shown in Figure $2 b$, based on the chemical quantification of the photoelectron spectra by peak-fitting with $\mathrm{Pt} 4 f$ electron. The XPS results of as-deposited film at $10 \%$ of $\mathrm{O}_{2} /\left(\mathrm{O}_{2}+\mathrm{Ar}\right)$ ratio shows that a mixture of pure $\mathrm{Pt}$ and $\mathrm{PtO}$ is formed. As the $\mathrm{O}_{2} /\left(\mathrm{O}_{2}+\mathrm{Ar}\right)$ gas ratio increases, the $\mathrm{PtO}$ component is found to increase, and $\mathrm{PtO}_{2}$ begins to be distinctly observed beginning at $30 \% \mathrm{O}_{2}$. As expected, the increase in the $\mathrm{O}_{2} /\left(\mathrm{O}_{2}+\mathrm{Ar}\right)$ ratio during deposition leads to an increase in the oxygen content in the as-deposited films, consistent with earlier work relating to $\mathrm{PtO}_{\mathrm{x}}$ by Hecq et. al. and McBride et. al.[26,27] Note that while the O/Pt atomic ratio should remain smaller or equal to 2, values above 3 are reported in Figure 2b. Given that 4+ is the highest oxidation state of $\mathrm{Pt}$ found in this study (for $\mathrm{PtO}_{2}$ ), the $\mathrm{O} / \mathrm{Pt}$ ratios greater than 2 obtained by XPS are likely due to contributions from adsorbed oxygen at the surface.

Cho et. al. similarly prepared porous Pt films by depositing them under a 50\% $\mathrm{O}_{2} /\left(\mathrm{O}_{2}+\mathrm{Ar}\right)$ ratio, followed by thermal annealing.[21] They found that porous films began to form above $600{ }^{\circ} \mathrm{C}$, and explained that the porous structure evolved by thermally activated agglomeration, following crystallization/reduction of the as-deposited $\mathrm{PtO}_{\mathrm{x}}$ film into Pt. By examining a wider range of conditions, we found, for example, that films deposited under lower $\mathrm{O}_{2} /\left(\mathrm{O}_{2}+\mathrm{Ar}\right)$ gas ratios than $25 \%$, even when annealed at $600{ }^{\circ} \mathrm{C}$ for 1 hour in air, showed no porous structure formation (see Figure 1). In addition, we found pores to form in under a minute, even at temperatures as low as $500{ }^{\circ} \mathrm{C}$, consistent with observations of Westwood et. al. that while the $\mathrm{PtO}$ phase is stable below $300{ }^{\circ} \mathrm{C}$, it begins to decompose into pure $\mathrm{Pt}$ above $500{ }^{\circ} \mathrm{C} .[25]$ This observation is supported by in-situ SEM observation as a function of temperature (see Supporting Information II). Therefore, we conclude that oxygen gas 
evolution from $\mathrm{PtO}_{\mathrm{x}}$ initiates and/or facilitates the formation of pores and that a critical minimum amount of oxygen incorporated within the Pt oxidic compounds (in the form of $\left.\mathrm{PtO}_{\mathrm{x}}\right)$ is required in order to form a porous structure.

The crystallographic properties of the thermally decomposed Pt films, following annealing, were studied by X-ray diffraction, as shown in Figure 3. Two main Pt peaks, (111) and (200), were observed for all films. Interestingly, the relative intensity of the (200) peak increased with increasing $\mathrm{O}_{2} /\left(\mathrm{O}_{2}+\mathrm{Ar}\right)$ ratio from $10 \%$ to $25 \%$, while it largely remained at an approximately constant ratio of $(200) /[(200)+(111)]$ for an $\mathrm{O}_{2} /\left(\mathrm{O}_{2}+\mathrm{Ar}\right)$ ratio $\sim 30 \%$. This observation is consistent with the SEM analysis, showing that the pore structure was formed above $\mathrm{O}_{2} /\left(\mathrm{O}_{2}+\mathrm{Ar}\right)$ ratio of $\sim 30 \%$. Further investigation with in-situ XRD measurement with high temporal resolution may help further clarify the pore formation mechanism.

Currently, many $\mu$-SOFCs designs operate with porous sputtered Pt electrodes, obtained by annealing dense, pure Pt films at elevated temperature.[3,7] Under these circumstances the Pt films break up and agglomerate as a result of Ostwald ripening.[39,40] This work is distinguished from this thermal agglomeration method, by the fact that pores are rapidly formed due to oxygen loss even before thermal agglomeration of the Pt layer can take place, as discussed above. Accordingly, this technique provides a major advantage over the agglomeration method, which requires much higher annealing temperatures $\left(650-800{ }^{\circ} \mathrm{C}\right)$ and longer times.[7] More importantly, the agglomeration method significantly limits the choice of the Pt layer thickness, given that agglomeration is highly sensitive to both annealing temperature and layer thickness and uniformity (See a map of film thickness and annealing temperature for porous structure formation in reference 7).[7] On the other hand, the method proposed in this study can provide a wide range of porous Pt layer thickness without significant change in morphology.

\subsection{Electrochemical properties of the porous Pt films}


The electrochemical performance of the porous Pt films under cathode operating conditions was investigated by electrochemical impedance spectroscopy as a function of the thickness of the Pt layer and the degree of porosity. For a comparison, the impedance spectra (IS) of a dense Pt film, prepared under pure Ar deposition gas, were also measured following the same thermal annealing condition of $600{ }^{\circ} \mathrm{C}$. The complex impedance spectra for the symmetrical structure, with identically sized $(9 \mathrm{~mm} \times 9 \mathrm{~mm})$ porous Pt electrodes (prepared with $\mathrm{O}_{2} /\left(\mathrm{Ar}+\mathrm{O}_{2}\right)$ ratio of $\left.70 \%\right)$ on both sides of the single crystal YSZ substrate, show contributions from two semicircles, as illustrated in Figure 4a. The impedance spectra were well-represented by two $R Q$ sub-circuits as shown in inset, where $R$ represents a resistance and $Q$ a constant phase element (CPE), respectively. CPEs are used to consider inhomogeneities in the electrodes, resulting in depressed arcs and deviating from expectations based on ideal capacitors.[8] Arc I, the high-frequency (HF) semicircle, is attributed to the series ohmic resistance of the YSZ single-crystal electrolyte. The behavior of this semicircle is quantitatively very similar for all films, as expected. The resistance, $\mathrm{R}_{\mathrm{HF}}$, derived from the equivalent circuit fitting, is characterized by an activation energy of 1.1 to $1.2 \mathrm{eV}$, is independent of $\mathrm{pO}_{2}$ and dc bias, as typical for the YSZ electrolyte. Further the conductivity, normalized to the electrolyte geometry, closely matches literature data for the ionic conductivity of YSZ (see Figure 4b). [41] Furthermore, as evident from Figure 4b, it is also independent of the Pt film thickness, within experimental error. One can thus confidently conclude that this IS feature should be solely attributed to the YSZ electrolyte and not the electrode. Accordingly, Arc II, the low-frequency (LF) semicircle, is believed to be due to the Pt electrode activation polarization with an activation energy of $1.24 \pm 0.03 \mathrm{eV}$, close to that reported for dense Pt microelectrodes $(1.36 \pm 0.11 \mathrm{eV})$.[42] The equivalent capacitance, computed according to $C=\left(R^{1-n} Q\right)^{1 / n}$, is at around $10^{-4} \mathrm{~F} / \mathrm{cm}^{2}$ which is characteristic of an interfacial effect. This second arc is depressed for all films, with an $n$ parameter as low as 0.6 -0.7 (for an ideal capacitance, $n=1$ ). The polarization resistance from the Pt electrode was 
estimated from equivalent circuit fitting, given that there is no additional impedance feature at an even lower frequency regime, as confirmed by measuring the impedance spectra at temperatures above $500{ }^{\circ} \mathrm{C}$ (data not shown in manuscript). Figure 4a compares the impedance spectra obtained for dense and porous Pt electrodes. Given the extremely high resistance from the dense Pt electrode, it was not possible to precisely extract its value at all measurement temperatures. Nevertheless, the estimated area specific resistance $(3.0 \pm 1.0 \times$ $10^{6} \Omega \cdot \mathrm{cm}^{2}$ at $375^{\circ} \mathrm{C}$ in air) of the nominally dense Pt electrode exhibited several orders of magnitude higher resistance than the Pt electrode with porous morphology $\left(8.0 \pm 0.1 \times 10^{4}\right.$ $\Omega \cdot \mathrm{cm}^{2}$ at $375{ }^{\circ} \mathrm{C}$ in air).

The electrode polarization conductance normalized to the nominal electrode area is plotted as a function of reciprocal temperature in Figure 5. For comparison, the reported values [7,21,43-46] for porous Pt electrodes prepared via paste and sputtering are also inserted in Figure 5. While many of the curves exhibit similar activation energies, the magnitude of electrode conductance is seen to differ by as much as 5 orders of magnitude between the various studies. Near linear correlations of electrode conductance with triple phase boundary length have been demonstrated, pointing to the key role played by the Pt morphology, in addition to possible effects associated with variations in chemical purity.[34] The present method provides a highly porous Pt geometry with an estimated triple boundary density of 65 $-80 \mathrm{~m} \cdot \mathrm{cm}^{-2}$ by SEM image analysis, comparable to the value of $15-150 \mathrm{~m} \cdot \mathrm{cm}^{-2}$ reported for porous Pt paste electrodes.[47] In addition, this technique ensures considerably higher purity, e.g., with respect to Si contamination,[34] compared with a typical platinum paste or a templated electrode, which often suffers from significant contamination issues and/or requires a high temperature annealing process $\left(>700^{\circ} \mathrm{C}\right)$. It is therefore not surprising that the porous Pt thin films prepared in this work provide amongst the highest electrode conductance reported in the literature (See Figure 5). 
Interestingly, within a similar range of temperatures, the electrode conductance of this work is within an order of magnitude of ones also prepared by sputtering either under pure Ar atmosphere followed by post-growth annealing ( $\square$ [7], or sputtering under high Ar deposition pressure $(\diamond)[7]$. However, while those porous Pt thin films, with thickness on the order of 50 $\mathrm{nm}$ and with nanoscopic pores, facilitate oxygen permeability, they are likely vulnerable to thermal agglomeration under long term annealing.[39] On the other hand, following $~ 76$ hours of electrochemical measurements at temperatures between $345^{\circ} \mathrm{C}-450{ }^{\circ} \mathrm{C}$ in air, the $150 \mathrm{~nm}$ thick porous Pt thin film investigated here showed no significant change in the porous structure or performance (see Supporting Information III). Furthermore, the method used in this study can be used to fabricate much thicker porous layers (> $500 \mathrm{~nm}$ ) with less likelihood for agglomeration. This suggests that the method employed in this study is not only straightforward and compatible with micro-fabrication processing, but can also provide superior long term performance as a SOFC cathode.

Interestingly, the electrode conductance exhibited little variation in magnitude as a function of deposition atmosphere (between $\mathrm{O}_{2} /\left(\mathrm{O}_{2}+\mathrm{Ar}\right)$ of $40 \%$ and $70 \%$ ) or Pt thin film thickness (see supporting Information IV). This is likely due to the fact that the porous film morphology does not vary sufficiently, within experimental error, with the variations in deposition atmosphere and film thickness applied in this study. Further reduction of the electrode polarization resistance, and in turn improved micro-SOFC fuel cell performance, will require additional control of film morphology, as well as, careful examination of the pore formation and cathode reaction mechanisms.

\section{Conclusion}

Porous Pt thin films were fabricated by reactive sputtering, followed by decomposition of the metastable Pt oxides to Pt metal during a brief high temperature treatment at $600^{\circ} \mathrm{C}$. The decomposition of $\mathrm{PtO}_{\mathrm{x}}$, and the subsequent oxygen gas evolution, played a controlling role in 
forming nanoporous structures with interconnected porosity when the $\mathrm{O}_{2}$ to argon ratio in the sputtering chamber exceeded $30 \%$. The method described in this study is compatible with micro-fabrication processing, providing a highly controlled morphology, characterized by nano-scale porosity and higher chemical purity, than achievable by previously reported methods. The resulting porous $\mathrm{Pt}$ thin films also demonstrate satisfactory performance comparable to the highest conductance of platinum film electrodes reported in the literatures, indicating this structure as a promising candidate for $\mu$-SOFC cathodes operated at $300{ }^{\circ} \mathrm{C}-450{ }^{\circ} \mathrm{C}$. In addition, given that thicker porous structure can be obtained in this manner, the method described in this study can be expected to provide better long term stability.

\section{Supporting Information}

Supporting Information is available online ....

\section{Acknowledgements}

This work was initially funded by the National Science Foundation under the World Materials Network (DMR-0908627) and subsequently by Basic Energy Sciences, U. S. Department of Energy (award DE-SC0002633). Additional support was provided by the Global Frontier R\&D Program on Center for Multiscale Energy System, funded by the National Research Foundation under the Ministry of Science, ICT \& Future, Korea (2011-0031569). JJK thanks The Kwanjeong Educational Foundation for fellowship support. The authors thank Dr. Woo Sik Kim for valuable discussions and aid with physical characterization.

Received: ((will be filled in by the editorial staff))

Revised: ((will be filled in by the editorial staff)) Published online: ((will be filled in by the editorial staff)) 


\section{REFERENCES}

[1] H.L. Tuller, S.J. Litzelman, W. Jung, Phys. Chem. Chem. Phys. 11 (2009) 3023.

[2] A. Bieberle-Hütter, D. Beckel, A. Infortuna, U.P. Muecke, J.L.M. Rupp, L.J. Gauckler, S. Rey-Mermet, P. Muralt, N.R. Bieri, N. Hotz, M.J. Stutz, D. Poulikakos, P. Heeb, P. Müller, A. Bernard, R. Gmür, T. Hocker, J. Power Sources 177 (2008) 123.

[3] A. Evans, A. Bieberle-Hütter, J.L.M. Rupp, L.J. Gauckler, J. Power Sources 194 (2009) 119.

[4] M. Tsuchiya, B.-K. Lai, S. Ramanathan, Nat. Nanotechnol. 6 (2011) 282.

[5] H. Huang, M. Nakamura, P. Su, R. Fasching, Y. Saito, F.B. Prinz, J. Electrochem. Soc. 154 (2007) B20.

[6] J.L. Hertz, H.L. Tuller, in:, A. Mitsos, P.I. Barton (Eds.), Microfabricated Power Generation Devices: Design and Technology, Wiley-VCH, Weinheim, Germany, 2009, pp. 51-80.

[7] T. Ryll, H. Galinski, L. Schlagenhauf, P. Elser, J.L.M. Rupp, A. Bieberle-Hutter, L.J. Gauckler, Adv. Funct. Mater. 21 (2011) 565.

[8] S.B. Adler, Chem. Rev. 104 (2004) 4791.

[9] H. Masuda, K. Fukuda, Science 268 (1995) 1466.

[10] M. Tiemann, Chem. Mater. 20 (2008) 961.

[11] Y.B. Kim, C.-M. Hsu, S.T. Connor, T.M. Gu $\square$ r, Y. Cui, F.B. Prinz, J. Electrochem. Soc. 157 (2010) B1269.

[12] Y. Ding, M. Chen, MRS Bull. 34 (2009) 569.

[13] D. V Pugh, A. Dursun, S.G. Corcoran, J. Mater. Res. 18 (2003) 216.

[14] J. Weissmüller, R.C. Newman, H. Jin, A.M. Hodge, J.W. Kysar, MRS Bull. 34 (2009) 577.

[15] a. Kloke, C. Kohler, a. Dryzga, R. Gerwig, K. Schumann, M. Ade, R. Zengerle, S. Kerzenmacher, J. Electrochem. Soc. 160 (2013) D111.

[16] C. Köhler, A. Kloke, A. Drzyzga, R. Zengerle, S. Kerzenmacher, J. Power Sources 242 (2013) 255.

[17] Y.-Y. Feng, J.-H. Ma, G.-R. Zhang, G. Liu, B.-Q. Xu, Electrochem. Commun. 12 (2010) 1191. 
[18] S. Tominaka, T. Hayashi, Y. Nakamura, T. Osaka, J. Mater. Chem. 20 (2010) 7175.

[19] M.J. Verkerk, W.J. Hommink, A.J. Burggraaf, J. Electrochem. Soc. 130 (1983) 70.

[20] R. Radhakrishnan, A. V. Virkar, S.C. Singhal, J. Electrochem. Soc. 152 (2005) A927.

[21] T.-S. Cho, H. Choi, J. Kim, J. Nanosci. Nanotechnol. 13 (2013) 4265.

[22] L.R. Velho, R.W. Bartlett, Metall. Trans. 3 (1972) 65.

[23] O. Muller, R. Roy, J. Less Common Met. 16 (1968) 129.

[24] A.K. Vijh, J. Electrochem. Soc. 119 (1972) 1498.

[25] W.D. Westwood, J. Appl. Phys. 45 (1974) 2313.

[26] M. Hecq, A. Hecq, J.P. Delrue, T. Robert, J. Less Common Met. 64 (1979) P25.

[27] J.R. McBride, G.W. Graham, C.R. Peters, W.H. Weber, J. Appl. Phys. 69 (1991) 1596.

[28] H. Neff, S. Henkel, E. Hartmannsgruber, E. Steinbeiss, W. Michalke, K. Steenbeck, H.G. Schmidt, J. Appl. Phys. 79 (1996) 7672.

[29] L. Maya, L. Riester, T. Thundat, C.S. Yust, J. Appl. Phys. 84 (1998) 6382.

[30] K.L. Saenger, C. Cabral, C. Lavoie, S.M. Rossnagel, J. Appl. Phys. 86 (1999) 6084.

[31] Y. Abe, M. Kawamura, K. Sasaki, Jpn. J. Appl. Phys. 38 (1999) 2092.

[32] Y. Abe, M. Kawamura, K. Sasaki, J. Vac. Sci. Technol. A Vacuum, Surfaces, Film. 18 (2000) 2608.

[33] G. V. Samsonov, The Oxide Handbook, n.d.

[34] J.L. Hertz, A. Rothschild, H.L. Tuller, J. Electroceramics 22 (2009) 428.

[35] A. Bieberle-Hütter, J.L. Hertz, H.L. Tuller, Acta Mater. 56 (2008) 177.

[36] L. Maya, G.M. Brown, T. Thundat, J. Appl. Electrochem. 29 (1999) 883.

[37] L. Maya, Method for Forming Porous Platinum Films, US Patent 6136704, 2000.

[38] G.M. Bancroft, I. Adams, L.L. Coatsworth, C.D. Bennewitz, J.D. Brown, W.D. Westwood, Anal. Chem. 47 (1975) 586.

[39] X. Wang, H. Huang, T. Holme, X. Tian, F.B. Prinz, J. Power Sources 175 (2008) 75.

[40] P.G. de Gennes, Rev. Mod. Phys. 57 (1985) 827.

[41] P. Abelard, U. Uersite, Phys. Rev. B 26 (1982) 1005. 
[42] A.K. Opitz, J. Fleig, Solid State Ionics 181 (2010) 684.

[43] J.E. Bauerle, J. Phys. Chem. Solids 30 (1969) 2657.

[44] S.P. Yoon, S.W. Nam, S.-G. Kim, S.-A. Hong, S.-H. Hyun, J. Power Sources 115 (2003) 27.

[45] J. Sasaki, J. Mizusaki, S. Yamauchi, K. Fueki, Solid State Ionics 3/4 (1981) 531.

[46] S.P.S. Badwal, M.J. Bannister, M.J. Murray, J. Electroanal. Chem. 168 (1984) 363.

[47] A. Mitterdorfer, L.J. Gauckler, Solid State Ionics 117 (1999) 203.

[48] J. Mizusaki, K. Amano, S. Yamauchi, K. Fueki, Solid State Ionics 22 (1987) 313.

[49] J. Mizusaki, K. Amano, S. Yamauchi, K. Fueki, Solid State Ionics 22 (1987) 323. 


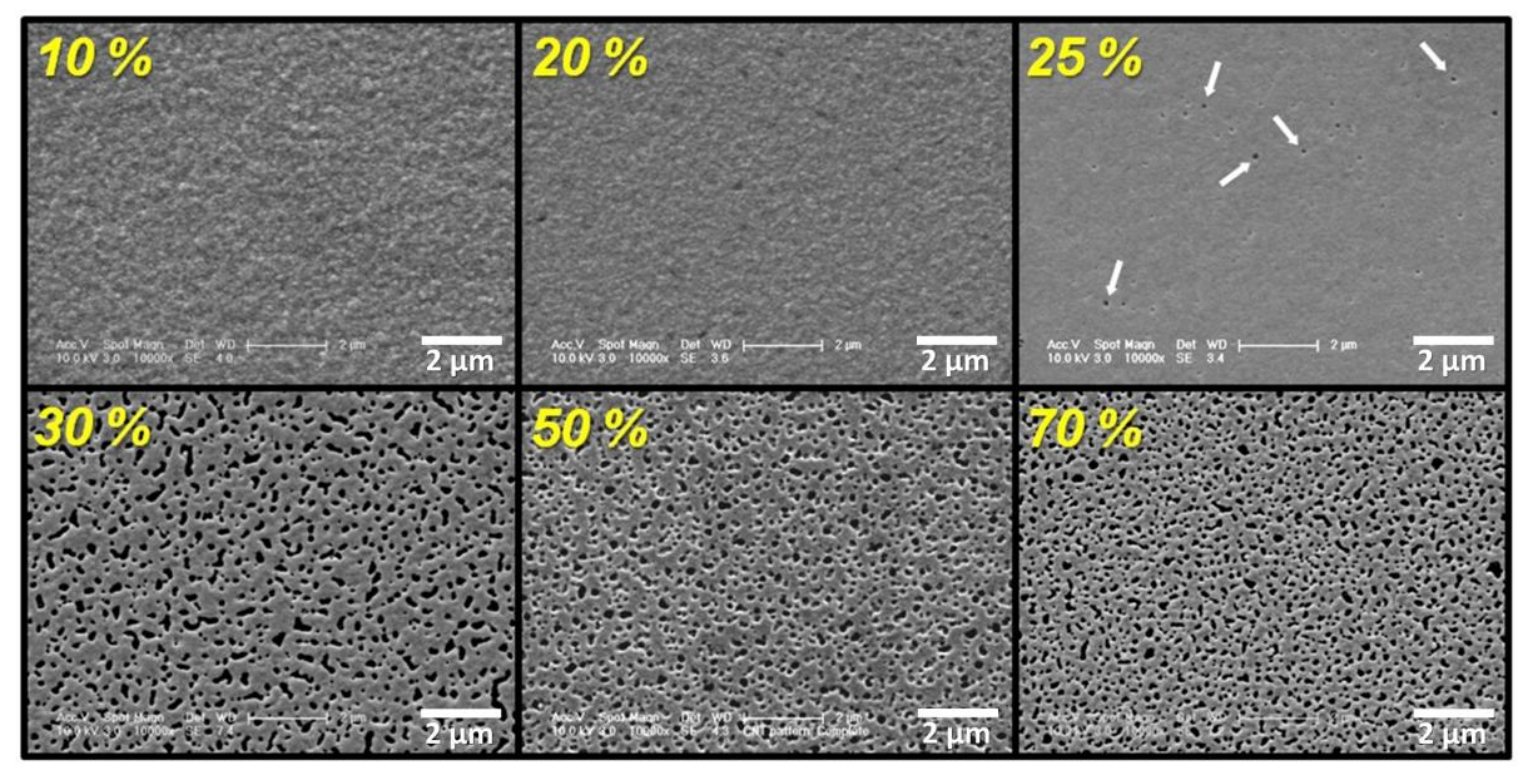

Figure 1. Scanning electron microscope micrographs of the resulting Pt films as a function of the oxygen ratio, $\mathrm{O}_{2} /\left(\mathrm{O}_{2}+\mathrm{Ar}\right)$ utilized during sputtering, following heating at $600^{\circ} \mathrm{C}$ in air for one hour. Pores, marked by arrows, begin to be appear at an $\mathrm{O}_{2} /\left(\mathrm{O}_{2}+\mathrm{Ar}\right)$ ratio of $25 \%$. All of as-deposited films have the same thickness $(\sim 200 \mathrm{~nm})$.
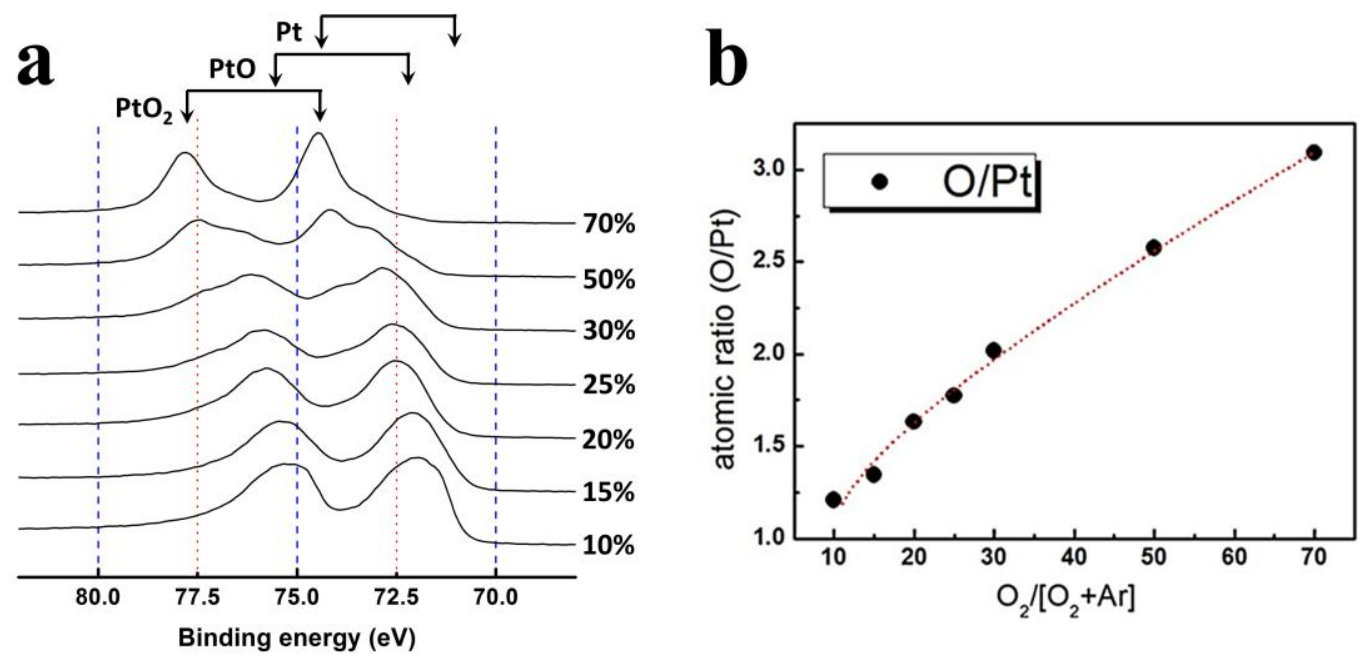

Figure 2. (a) XPS spectra of Pt $4 f$ electrons in as-deposited films vs. oxygen gas ratio before annealing. While pure $\mathrm{Pt}$ shows two energy states at $71.2 \sim 3 \mathrm{eV}$ and $74.6 \mathrm{eV}$ for $4 f_{7 / 2}$ and $4 f_{5 / 2}$, respectively, the corresponding energy states of $\mathrm{PtO}$ and $\mathrm{PtO}_{2}$ are shifted to higher energy 
such as 72.3 4 eV / 75.6 7 eV and 73.6 74.2 eV / 76.8 77.5 eV, respectively.[26,38] (b) Atomic ratio of $\mathrm{O}$ to $\mathrm{Pt}$ in the as-deposited films.
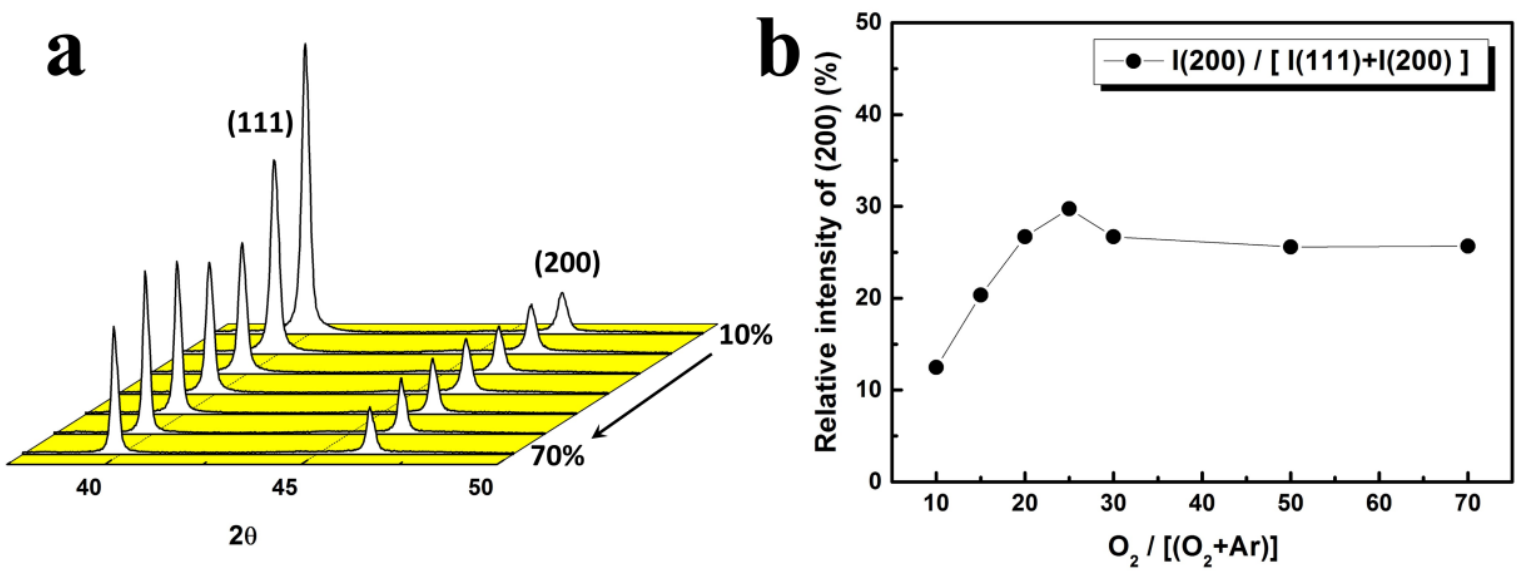

Figure 3. (a) XRD pattern of a $200 \mathrm{~nm}$ thick Pt film after annealing at $600{ }^{\circ} \mathrm{C}$ as a function of $\mathrm{O}_{2} /\left(\mathrm{O}_{2}+\right.$ Ar) gas ratio during sputtering. (b) Relative intensity of (200) orientation with respect to (111) vs. $\mathrm{O}_{2} /\left(\mathrm{O}_{2}+\mathrm{Ar}\right)$ gas ratio. 


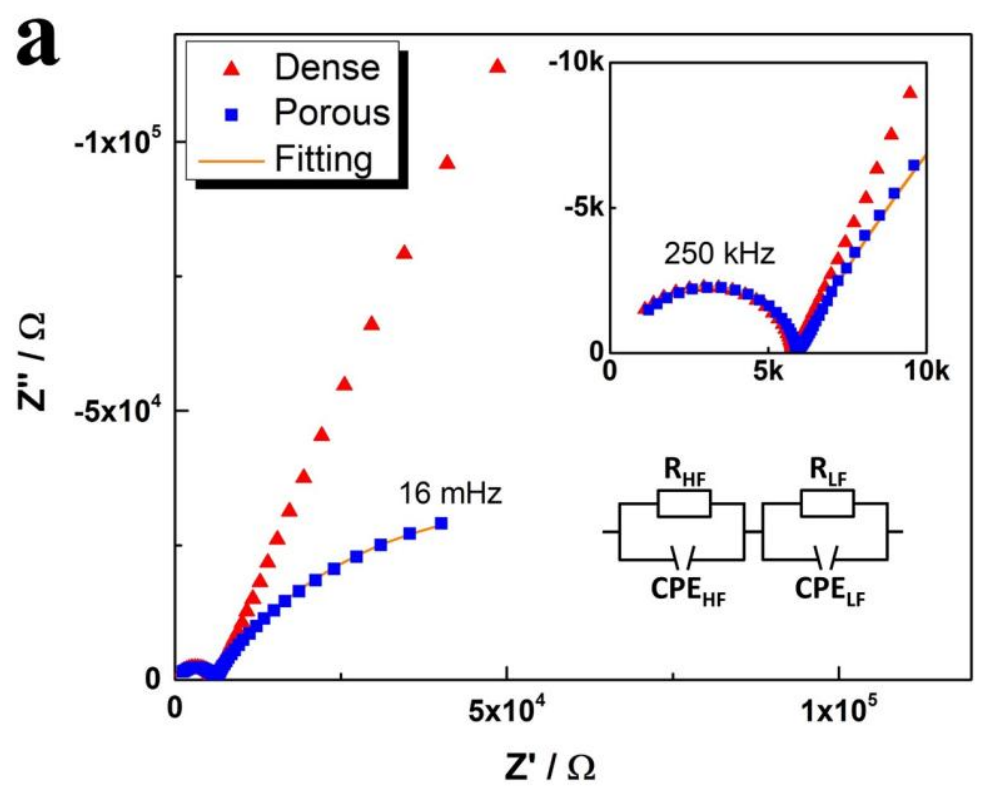

Temperature $/{ }^{\circ} \mathrm{C}$

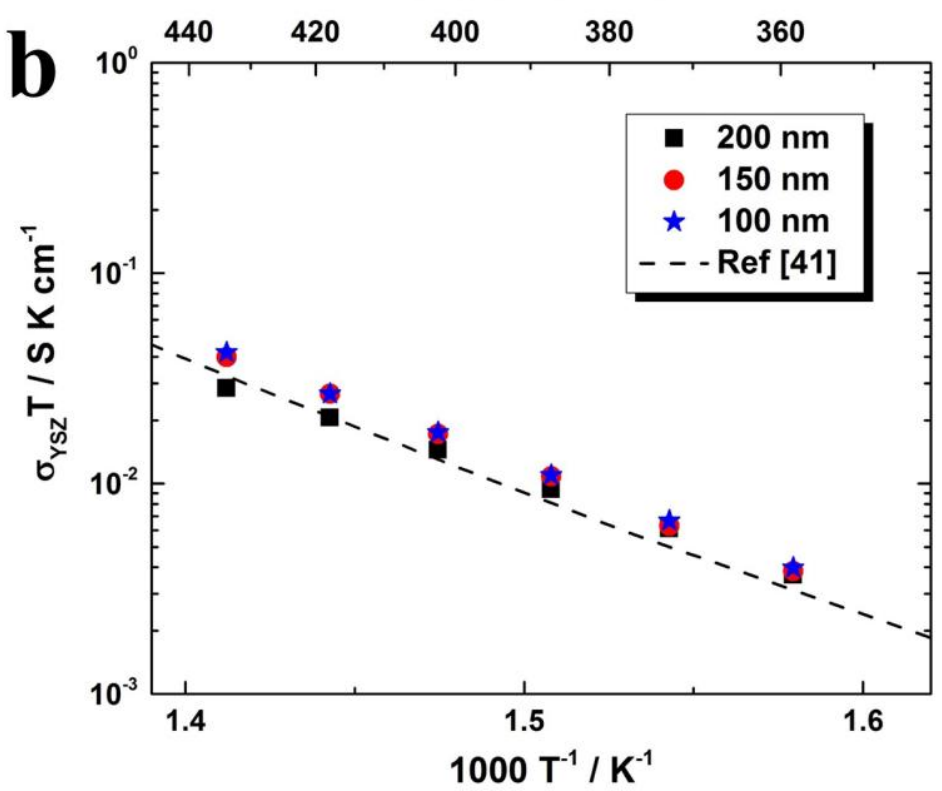

Figure 4. (a) Typical impedance spectra of dense (triangle) and porous (square) Pt electrodes deposited on a YSZ single crystal measured in air at $375^{\circ} \mathrm{C}$. The fitting result (solid line) for porous Pt electrode modeled with the equivalent circuit (inset) is included. The approximate peak frequencies of the high frequency semicircles are indicated in the figure. The dense electrode was prepared with pure Ar as the deposition gas, while the porous film was grown in an atmosphere of $70 \% \mathrm{O}_{2}$ in $\mathrm{Ar}+\mathrm{O}_{2}$, followed by a high temperature anneal. Both 
electrodes were prepared under the same total pressure of $10 \mathrm{mTorr}$ and DC power of $50 \mathrm{~W}$. (b) Log electrical conductivity - temperature product vs $1000 / \mathrm{T}$ assigned to YSZ singlecrystal electrolyte, as derived by appropriate fitting of the high frequency IS features. Reported conductivity values from the literature are also inserted for comparison, (dashed line).

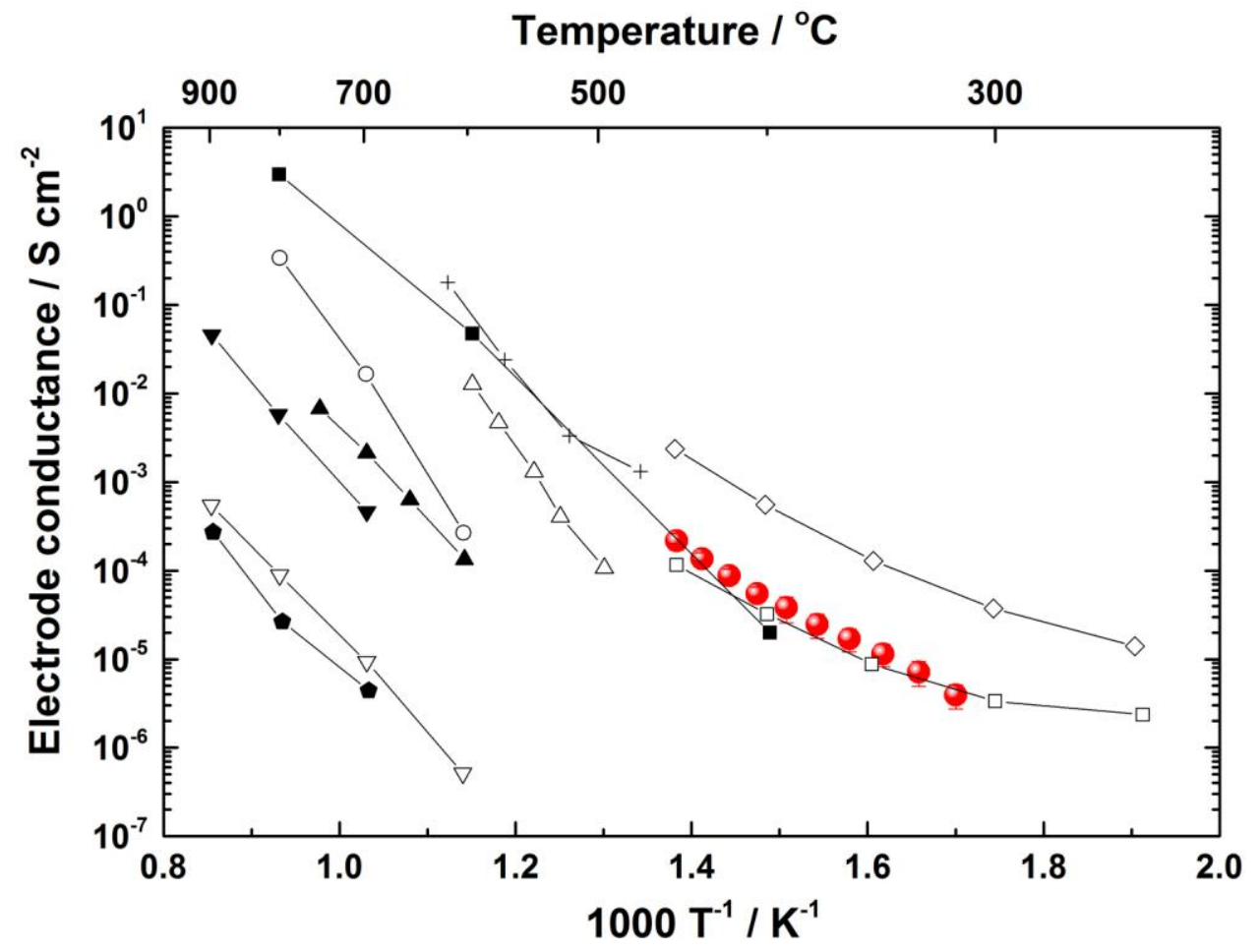

Figure 5. Arrhenius plot of electrode conductance (normalized) for the porous Pt electrode in this study (solid red circles). For comparison, previously reported electrode conductance (normalized) values for porous Pt electrodes are also inserted. Reactively sputtered: $+[21]$;

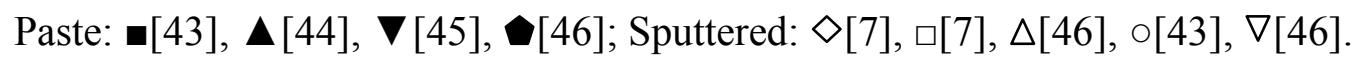




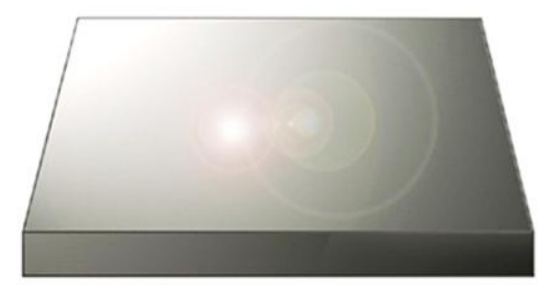

$\mathrm{O}_{2}$ reactive sputtered $\mathrm{Pt} / \mathrm{O}$ film

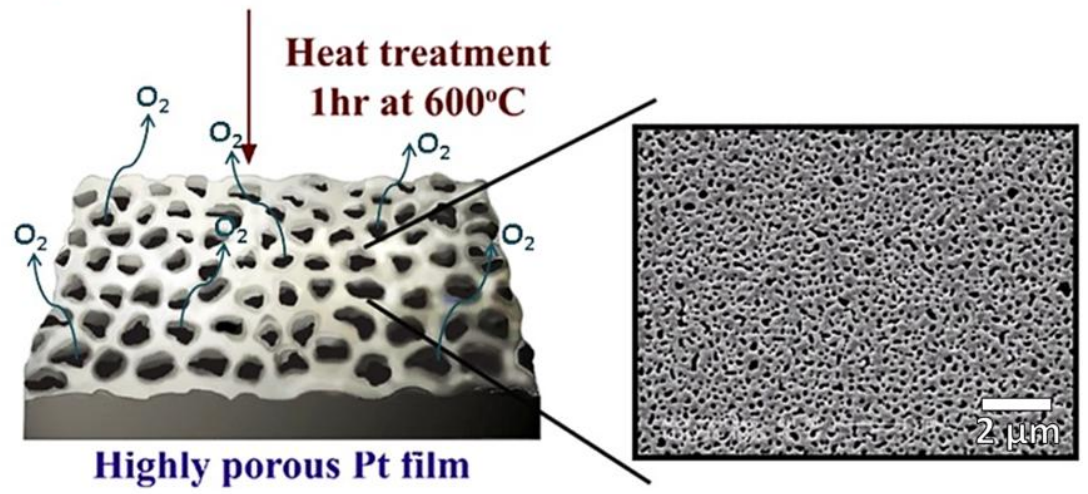

Revised graphical abstract 